\title{
Eddies and Upper-Ocean Nutrient Supply
}

\begin{abstract}
A. Oschlies
IFM-GEOMAR, Leibniz-Institut für Meereswissenschaften an der Universität Kiel, Kiel, Germany

The role of mesoscale eddies in biogeochemical cycles is reviewed with a focus on the nutrient supply to the oligotrophic gyres. Previous estimates of the eddyinduced nutrient supply differ by an order of magnitude, which can be related to different assumptions made about timescales for nutrient consumption and subsequent recharging of nutrient-depleted waters. Results from a fully prognostic eddy-resolving ecosystem-circulation model reveal a magnitude of eddy-induced nitrate supply to the North Atlantic subtropical gyre of typically less than $0.05 \mathrm{~mol}$ $\mathrm{m}^{-2}$ year $^{-1}$. This number includes the contribution by lateral eddy stirring which, on average, is larger than that by vertical eddy pumping. The results are in line with earlier conservative estimates and suggest that previous high estimates of the nutrient supply by eddy pumping have been overestimates.
\end{abstract}

\section{INTRODUCTION}

Observations of mesoscale variability in the color of surface sea water were reported and linked to marine biology already by the great explorers of the eighteenth century, among them Captain James Cook [Bainbridge, 1957]. Nowadays, ubiquitous meso- and sub-mesoscale variations in upper-ocean optical properties are perhaps most spectacularly seen from space, examples including the "line in the sea" recorded on camera by the space shuttle astronauts [Yoder et al., 1994], features associated with equatorial [Strutton et al., 2001] and off-equatorial Rossby waves [Uz et al., 2001; Kawamiya and Oschlies, 2001; Dandonneau et al., 2003] or mid-latitude mesoscale patchiness [Martin, 2003]. In situ studies using towed instruments have also provided in-depth views of mesoscale and sub-mesoscale features [Fasham et al., 1985; Strass, 1992; Washburn et al., 1998].

A global analysis of mesoscale ocean color variability as seen by the sea-viewing wide field-of-view sensor (Sea WiFS) satellite confirmed the global applicability of earlier local and regional findings that small-scale variability

Ocean Modeling in an Eddying Regime

Geophysical Monograph Series 177

Copyright 2008 by the American Geophysical Union. 10.1029/177GM09 in ocean biology is closely linked to ocean physics [Doney et al., 2003]. Length scales of mesoscale ocean color variability are similar to those estimated from satellite altimeter data and are often related to the first baroclinic Rossby deformation radius. However, the strong west-east asymmetry observed for physical eddy kinetic energy is much less visible in the ocean color data. Significant ocean color variability can also be seen at the sub-mesoscale $(<10 \mathrm{~km})$ where scales emerge as a complex interplay of different timescales associated with growth, respiration, and trophic interactions with physical turbulent advection and stirring [Abraham, 1998; Garçon et al., 2001; Mahadevan and Campbell, 2002].

Mesoscale features impact upper-ocean biology through a number of processes, including lateral advection and stirring [Lee and Williams, 2000], frontal instabilities and the associated tilting of isopycnal surfaces [Woods, 1988; Nurser and Zhang, 2000], frontal upwelling [Onken, 1992], and the eddy pumping mechanism according to which the formation and intensification of cyclonic eddies can lift nutrientreplete isopycnals into the light [Jenkins, 1988; Falkowski et al., 1991; McGillicuddy and Robinson, 1997], possibly altered by the interaction of the eddy's surface currents with the wind field [Martin and Richards, 2001; McGillicuddy et al., 2007]. Recent reviews of these processes and the way they influence marine ecosystems include those by Garçon 
et al. [2001] and Williams and Follows [2003]. The present study focuses on the role eddies play in supplying nutrients to the light-lit upper ocean and thereby fueling biological production and driving biogeochemical cycles.

\section{WHY BOTHER?}

\subsection{The Biological Carbon Pump}

The biotically mediated export of organic carbon from the surface of the ocean toward its interior is a crucial component of the global carbon cycle. This so-called biological pump [Volk and Hoffert, 1985] is responsible for the observed vertical nutrient gradient between the surface ocean, which is generally depleted, and deeper nutrient-rich water. Because of the relatively constant carbon-to-nutrient stoichiometry of marine organic matter, the biological pump is also responsible for a large portion (about three quarters) of the observed vertical gradient of dissolved inorganic carbon. Without the biology acting, the surface concentrations of nutrients and dissolved inorganic carbon would be much larger, resulting in approximately doubled concentrations of atmospheric carbon dioxide $\left(\mathrm{CO}_{2}\right)$ [Maier-Reimer et al., 1996].

When linking biological production and the biological pump, a few concepts are relevant. First, only that portion of the total primary production that is not immediately recycled within the upper ocean can contribute to the observed vertical gradients in biogeochemical tracers. This portion is called "new production", which is defined by Dugdale and Goering [1967] as the primary production in the euphotic zone that results from nitrogen input from outside the euphotic zone, i.e., inputs from the water below, from land, or from the atmosphere. In a steady state, new production must equal the export of photosynthetically fixed organic matter to the deep ocean [Eppley and Peterson, 1979]. This balance does not necessarily hold locally, as lateral advection of nutrients and/or biomass may regionally decouple areas of nutrient supply from areas of biomass export [Oschlies, 2002c; Plattner et al., 2005].

Dugdale and Goering [1967] used the euphotic zone (the zone with sufficient light levels for photosynthesis to occur) as the depth range to define new production. Air-sea exchange of $\mathrm{CO}_{2}$, however, does not depend on light but only on material contact with the air-sea interface. In this respect, the surface mixed layer is the appropriate depth range [Oschlies and Kähler, 2004]. As a matter of fact, there is often little difference between the depth ranges of the euphotic zone and the surface mixed layer in the subtropics and summertime mid-latitudes where many of the observational studies have been undertaken and where much of this paper will focus. Nevertheless, in this paper, we will focus mainly on eddy impacts on new production and export production, which both use the base of the euphotic zone as the reference depth. We thus do not explicitly examine the impacts of eddies on mixed-layer depths, although a net eddy-induced shallowing of high-latitude winter mixed-layer depths has been suggested [Oschlies, 2002b]. Impacts on new production can also be traced to impacts on primary production and, to some extent, to changes in surface partial pressure of $\mathrm{CO}_{2}\left(\mathrm{pCO}_{2}\right)$ [Mahadevan et al., 2004]. Linking new production to air-sea carbon fluxes is not always straightforward and requires careful consideration of the differences between mixed-layer depth and euphotic-zone depth as well as the different relevant timescales which are typically days to weeks for biological production and months for air-sea gas exchange [Oschlies and Kähler, 2004].

\subsection{A Case for Eddying Nutrient Supply}

Concentrating on the role played by eddies in global biogeochemical cycles, we begin by looking at the annual mean "climatological" nitrate field compiled from a large number of observations by Conkright et al. [2002]. A very similar picture exists for phosphate, the other major nutrient essential for biological production. A dominant feature is the depletion of these essential nutrients in the surface waters of the subtropical gyres (Figure 1). A vertical section of the zonally averaged nitrate field shows bowl-shaped nutrientpoor regions in and above the subtropical thermocline.

The presence of closed temporal-mean surfaces of constant nitrate concentration, $\mathrm{NO}_{3}=$ const (as indicated by closed contours in Figure 1 in the zonal average and in the surface layer), already points at the potential role of eddies in fueling nutrient supply to the nutrient-poor subtropical gyres. Consider some $\mathrm{NO}_{3}=$ const surface (for example $\mathrm{NO}_{3}=5 \mathrm{mmol} \mathrm{m}^{-3}$ ) that, in the annual mean, encloses some low-latitude water volume $V$. Assuming mass (and, for an incompressible fluid, volume) conservation by neglecting any net precipitation-minus-evaporation across the sea surface bounded by the $\mathrm{NO}_{3}=$ const contours, Gauß's theorem then tells us that the mean advection of the mean nitrate field cannot yield any net transport of nitrate across any closed $\mathrm{NO}_{3}=$ const $=\mathrm{NO}_{3}^{*}$ surface:

$$
\begin{aligned}
\int_{V\left(\mathrm{NO}_{3} \leq \mathrm{NO}_{3}^{*}\right)} \nabla \cdot\left(\mathbf{u N O}_{3}\right) d^{3} x & \left.=\int_{\mathrm{NO}_{3}=\mathrm{NO}_{3}^{*}}(\mathbf{u N O})_{3}\right) \cdot \mathbf{n} d A \\
& =\mathrm{NO}_{3}^{*} \int_{\mathrm{NO}_{3}=\mathrm{NO}_{3}^{*}}(\mathbf{u} \cdot \mathbf{n}) d A \\
& =\mathrm{NO}_{3}^{*} \int_{\mathrm{V}} \nabla \cdot \mathbf{u} d^{3} x=0
\end{aligned}
$$

where $\boldsymbol{u}$ and $\mathrm{NO}_{3}$ denote annual mean velocity vector and nitrate concentration, respectively. This argument, put forward 


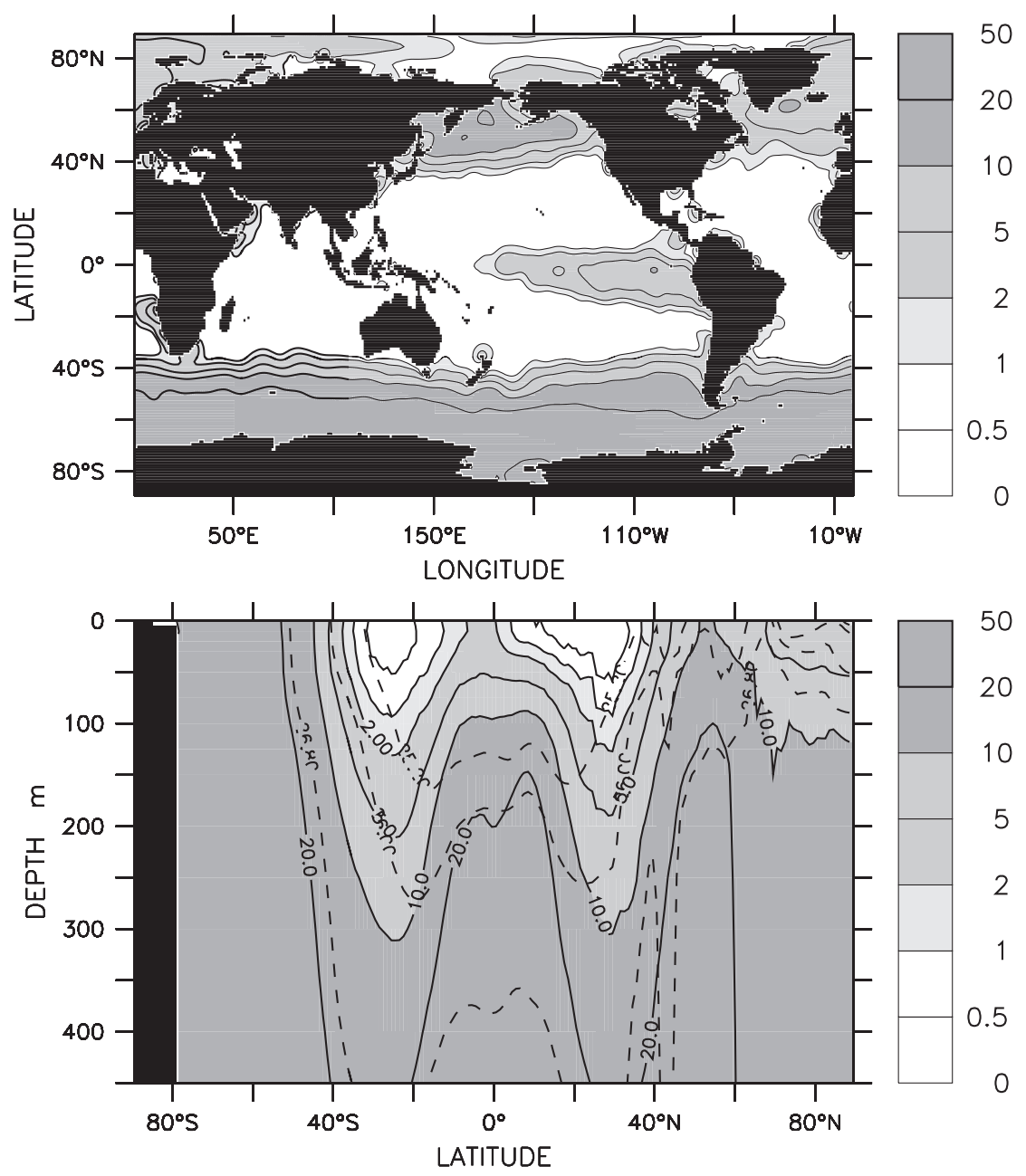

Figure 1. Top: Annual-mean surface nitrate concentrations. Bottom: Zonally averaged nitrate field. The zonal mean positions of the $\sigma=25.2, \sigma=26.0$, and $\sigma=26.8$ isopycnals are indicated by the dashed lines. Units are $\mathrm{mmol} \mathrm{m}^{-3}$. Data are taken from the World Ocean Atlas 2001 [Conkright et al., 2002].

for ocean heat transport by Greatbatch et al. [2007], means that irrespective of biological nitrate sinks and sources, which affect the nitrate field and thus the location and shape of the nitrate iso-surfaces, a steady circulation cannot be a net supplier of nutrients to the tropical and subtropical areas enclosed by a mean $\mathrm{NO}_{3}=$ const surface. This does not rule out advective transport across individual areas of this surface, but according to Gauß's theorem, this transport happens in such a way that the total advective transport of nitrate integrated over the closed surface vanishes. Therefore, any export of organic matter out of a volume enclosed by a mean $\mathrm{NO}_{3}=$ const surface cannot be fueled by a steady advective nutrient supply.

The following model diagnostics will not be performed on nitrate surfaces but rather on grid levels of the model that, in turn, can be interpreted as the nominal base of the euphotic zone. In this respect, Gauß's theorem has limited practical value, other than demonstrating in a mathematically clean way the general importance of temporal variability and/or mixing for nutrient supply over large parts of the global ocean. Were it not for diffusive transport and temporal variability in nitrate concentrations, in velocities or in both, export production in the subtropical gyres would depend solely on nutrient supply by means of nitrogen fixation, rivers, sediments, or the atmosphere.

\subsection{Subtropical Desert Conundrums}

The subtropical gyres have been in the center of a number of controversies over the past decades. Over these regions, the surface depletion of the essential nutrients nitrate and phosphorus is particularly pronounced (Figure 1). Ekman 
downwelling and a stably stratified pycnocline limit reentrainment of nutrients into the light-lit surface layer and, even in winter, the surface mixed layer does not significantly exceed the depth of the euphotic zone. Accordingly, the subtropical gyres are often referred to as the ocean deserts [Williams and Follows, 1998b], and they display the lowest chlorophyll concentrations and clearest surface waters of the world ocean [Morel et al., 2007]. Still, biological production is not zero, and there is ample evidence for substantial new production and export production in these areas. Indirect geochemical estimates of both nutrient supply to the light-lit surface layer, either from oxygen production in the euphotic zone [Jenkins and Goldman, 1985; Spitzer and Jenkins, 1989], from oxygen consumption in the aphotic zone underneath [Jenkins, 1982; Sarmiento et al., 1990], or from a correlation between helium and nitrate (the so-called He flux gauge [Jenkins, 1988]), all suggest levels of export production (about $0.4-0.6 \mathrm{~mol} \mathrm{~N} \mathrm{~m}^{-2}$ year $^{-1}$ if converted to nitrogen using Redfield ratios). A first conundrum is that such values, which are not very different from estimates in mesotrophic and eutrophic areas in mid and high latitudes, are substantially higher than direct biological and physical measurements of nitrate supply and uptake [Lewis et al., 1986] and of particle export [Lohrenz et al., 1992] could account for. A second conundrum addresses the magnitude and even the direction of the biotic contribution to air-sea $\mathrm{CO}_{2}$ fluxes over the subtropical oceans. A number of observations suggest that respiration exceeds primary production already within the euphotic zone [e.g., del Giorgio et al., 1997; Williams et al., 2004]. Without lateral or atmospheric input of organic carbon, the net respiration would leave no organic carbon that could be exported out of the euphotic zone into the ocean interior.

The mismatch of geochemical tracer-based and direct estimates of nutrient supply and export production in the subtropical gyres has often been attributed to the different time and space scales the different measurements correspond to: the geochemical estimates integrate over hundreds to thousands of kilometers and years to decades, whereas the direct measurements reflect local and instantaneous conditions. Undersampling of episodic events like nutrient injections by mesoscale eddies (see subsequent section) might have led to their under-representation in the direct measurements. Similar arguments may be put forward with respect to the trophic state of the ocean: primary production can be expected to respond faster to changes in environmental conditions and therefore be more sensitive to episodic events than is respiration [Karl et al., 2003]. However, undersampling alone does not systematically bias the results and therefore does not explain the direction of the apparent imbalances between production and export or between production and respira- tion (other than giving each a $50 \%$ chance). Statistically, the chances of over-representation of episodic events in any data set are equal to the chances of under-representation. The likelihood of systematic sampling biases should be particularly small for eddy-type features at the long-term timeseries sites in the subtropical oceans, the Bermuda Atlantic Time-Series Study (BATS) and the Hawaii ocean timeseries with typical sampling intervals (monthly to fortnightly) similar to the lifetime of eddy signals [e.g., McNeil et al., 1999].

It is noteworthy that issues other than episodic events may be relevant for explaining the apparent observational discrepancies. For example, additional nitrogen sources such as nitrogen fixation or atmospheric deposition may significantly contribute to total nutrient input and affect the trophic state of the ecosystem. Erroneous assumptions about stoichiometric relations may be relevant when combining estimates of nutrient supply with concepts of primary production and export production, which are usually formulated in carbon units. Here, we will not further explore these alternative aspects and instead concentrate on the role of episodic events associated with eddies.

\section{EDDY PUMPING}

A possible scenario whereby eddies may lead to a net increase in nutrient supply to the euphotic zone, and hence biological production, is based on the vertical asymmetry of the light field. Although upward and downward excursions of water parcels due to eddies will average out, nutrients can be more readily taken up when water parcels are moved upward into the light. This concept rests on the fact that within cyclonic eddies and, in parts of the subtropics also within anticyclonic mode water eddies [McGillicuddy et al., 1999], isopycnals are displaced upwards and thereby may move deep and nutrient-rich waters into the euphotic zone. Depending on how long the upwelled water stays in the light, some or all of the upwelled nutrients can be consumed by new production. Within anticyclonic eddies, on the other hand, isopycnal surfaces are displaced downwards. This moves nutrients further away from the euphotic zone, but does not give rise to any major biological response.

A few observations of the process, often termed "eddy pumping," exist but vary with respect to the interpretation of its long-term and basin-scale significance [Falkowski et al., 1991; McGillicuddy et al., 1998; McNeil et al., 1999]. Based on detailed observations of a cyclonic eddy in the subtropical North Pacific, Falkowski et al. [1991] inferred some average $20 \%$ increase in primary production due to eddies. From observations near Bermuda, McGillicuddy et al. [1998] estimated that eddy pumping could increase the nutrient supply 
by more than $100 \%$. Obviously, extrapolation of the observed individual events to larger space and longer timescales is difficult. Moreover, interpretations and possible extrapolations of local observations will depend on the extent to which the observed features behave more like waves or like eddies. Wave-like features will move water up and down locally. Closed eddies, on the other hand, can displace water vertically during the eddy formation and then move the enclosed water laterally with only a small vertical component due to eddy decay. Observed property differences with respect to the local background may therefore not reflect local processes, but will be affected by the remote history of the observed eddy. Extrapolations from local observations are difficult to achieve, and synoptic satellite observations and numerical models may both help to accomplish this in a consistent way.

\subsection{Satellite-Based Estimates}

Satellite-based estimates of the contribution of eddy pumping to new production in the Sargasso Sea were presented by McGillicuddy et al. [1998] and Siegel et al. [1999]. Using satellite altimeter data and statistical regressions derived from in situ observations at the BATS site, they assumed that all negative sea surface height (SSH) anomalies were associated with upward displacements of climatological nitrate profiles and that all nitrate entering the euphotic zone was used up completely during the lifetime of the negative SSH anomaly. The resulting estimates of nutrient supply associated with eddy pumping were $0.19 \pm 0.1$ and $0.24 \pm 0.1 \mathrm{~mol} \mathrm{~N} \mathrm{~m}^{-2}$ year $^{-1}$ for the two studies, respectively, and thereby account for about half of the new production estimated from geochemical tracers.

As discussed by Martin and Pondaven [2003], the Siegel et al. [1999] method relies on two assumptions that are mutually exclusive, namely that $100 \%$ of the upwelled nitrate is taken up and exported by the biology and that there is sufficient time between successive eddy events to recharge background nitrate to climatological levels. For observed eddy statistics at the BATS site, Martin and Pondaven estimated that not more than about $50 \%$ of the nitrate could be taken up locally and that, in addition, recharging of nitrate inventories between successive eddy events cannot be complete. Applying the Siegel et al. [1999] method to an eddy-resolving coupled ecosystemcirculation model for estimating the eddy-associated flux in the model, Oschlies [2002a] found this estimate to be sixfold larger than the "true" eddy flux calculated from the threedimensional circulation and biological dynamics.

\subsection{Recharging Issues}

The issue of recharging becomes more evident when one looks at eddy pumping in an isopycnal framework. An initial upward displacement of an isopycnal into the light may lead to new production and eventually to sinking of particulate organic matter. As sinking is always relative to the ambient water, in a stably stratified pycnocline, sinking is a diapycnal transport. Remineralization will then release the nutrients on denser (and locally deeper) density surfaces than the original one on which the eddy-driven new production had taken place. Recharging the original isopycnal with nutrients will therefore require some diapycnal transport counteracting the diapycnal sinking flux. Such a diapycnal transport could be caused by local diapycnal mixing or by remote diapycnal mixing or water mass transformation in combination with isopycnal transport to the location of interest. The bottom line is that without diapycnal processes, eddies would simply lead to a net deepening of the nutricline by allowing depletion of all isopycnals that can occasionally be moved into the light by eddies. A similar effect could be obtained in a thought experiment by increasing the penetration of light in a non-eddying ocean by a few tens of meters according to the eddy distribution of an eddying ocean. After an initial increase in export production during the first very few deeper light pulses, total new production would again be close to the original levels and be controlled by diapycnal transport of nutrients across the stably stratified nutricline.

The above argument suggests that the one-dimensional concept of eddy pumping cannot work unless there is some extra diapycnal nutrient transport associated with the eddies. There are at least three reasons why eddies may indeed increase diapycnal mixing. First, the additional curvature of the isopycnal surfaces increases the surface area across which turbulent mixing can flux tracers. Second, the kinetic energy of the eddy generates areas of enhanced velocity shear, increasing the likelihood of shear instabilities. Third, by means of interactions with the surface mixed layer, eddies can contribute to water mass modification and thereby change the density class of water parcels [Radko and Marshall, 2004]. As these mechanisms include lateral processes in addition to vertical ones, we will now look at fully three-dimensional studies of the impact of eddies on the upper-ocean nutrient supply.

\section{EDDY-RESOLVING MODELS}

\subsection{Regional Models}

A number of regional high-resolution models have shown that substantial vertical velocities can be associated with mesoscale variability. For an unstable meandering front. Onken [1992] found alternating vertical velocities of typically $10 \mathrm{~m}$ day $^{-1}$. The additional input of nutrients to the euphotic zone caused by the eddy-induced vertical motions was modelled by Flierl and Davis [1993] for Gulf Stream meanders, suggesting 
a mean enhancement of phytoplankton biomass by $10-20 \%$. A similar, quasi-geostrophic model setup for the North Equatorial Current by Dadou et al. [1996] showed that biological production within the frontal zone was about twice that of the background values.

An early modeling study of an individual eddy by Franks et al. [1986] revealed some additional nutrient supply during the spin-down of an anticyclonic warm-core ring. Eddy-eddy interactions were identified in a model of two warm core rings by Yoshimori and Kishi [1994] as the main mechanism responsible for the enhanced biological production simulated at the margins of the eddies. McGillicuddy et al. [1995] used a similar approach to study three eddies observed during the Joint Global Ocean Flux Study North Atlantic Bloom Experiment. Employing a quasi-geostrophic model, their findings suggested that the lifting of density surfaces during eddy propagation and interaction with the ambient water and with other eddies was dominating eddyinduced nutrient fluxes compared to minor contributions caused by vortex stretching and interactions with winddriven motions. A comprehensive study by Spall and Richards [2000] elegantly combined Eulerian and Lagrangian modeling to show that eddies shed along a front can locally and temporarily enhance biological production by an order of $100 \%$, but then the net increase is "only" of the order of $10 \%$ when averaged over the entire frontal area at the end of their 45-day integration. With a horizontal resolution of $2 \mathrm{~km}$, their isopycnic model was even resolving a substantial portion of the sub-mesoscale spectrum. A similarly high spatial resolution and a similar model setup of an idealized unstable front was used by Lévy et al. [2001] for a $z$-level primitive-equation model. Their somewhat shorter model runs (25 days) revealed an increase in biological production by about $100 \%$ when mesoscale and sub-mesoscale motions were included.

To obtain a more realistic physical environment, Mahadevan and Archer [2000] set up a regional primitive-equation model with sigma-type vertical coordinates. The model was forced at its open boundaries with output taken from a high-resolution global circulation model. By running their nested model for three late summer months over regions in the subtropical North Pacific (near Hawaii) and North Atlantic (near Bermuda), they found that simulated upperocean nutrient supply increased by an order of magnitude, for example in the Bermuda region from $0.03-0.05 \mathrm{~mol} \mathrm{~N}$ $\mathrm{m}^{-2}$ year $^{-1}$ at $0.4^{\circ}$ resolution to $0.30-0.54 \mathrm{~mol} \mathrm{~N} \mathrm{~m}^{-2}$ year $^{-1}$ at $0.1^{\circ}$ resolution. It is interesting to note that their results also showed that modelled surface temperatures were, on average, $0.36^{\circ} \mathrm{C}$ colder $\left(0.47^{\circ} \mathrm{C}\right.$ at Hawaii) in the 3 -month, $0.1^{\circ}$ resolution run compared to the $0.4^{\circ}$ resolution run. Assuming this eddy-induced cooling to affect the top $100 \mathrm{~m}$ of the ocean, this corresponds to a surface heat-flux difference of $28 \mathrm{~W} \mathrm{~m}^{-2}\left(36 \mathrm{~W} \mathrm{~m}^{-2}\right.$ at Hawaii) between the two runs. Obviously, the enhanced mixing that goes along with higher eddy activity does not only mix nutrients up to the surface but also mixes heat down the thermocline. To the extent that we can limit uncertainties in surface heat fluxes to about 20 $30 \mathrm{~W} \mathrm{~m}^{-2}$, we may be able to use this information to constrain the magnitude of eddy-induced nutrient supply. For a basinscale eddy-permitting model, Oschlies [2002c] revealed a systematic overestimation of subtropical heat uptake by some $25 \mathrm{~W} \mathrm{~m}^{-2}$ in response to simulated surface temperatures being too low by about $0.5^{\circ} \mathrm{C}$. This may suggest that there is already too much diapycnal mixing in the model leading to excessive downward transport of heat and likely excessive upward transport of nutrients.

A notorious difficulty of all of the aforementioned regional models is that these cannot usually be run stably for longer than a few months. This makes it difficult to model entire "life cycles" of individual eddies, and the results will always be affected by the initial conditions and boundary conditions set to initiate the eddy field. Even if one gets the eddy-induced mixing intensity right, the mean tracer gradients, which also will determine the eddy-induced tracer transport [Lévy, 2003], may not have enough time to adjust to the simulated eddy field in short spin-up or spin-down experiments. Substantially longer simulations require larger domains that reduce the impact of imposed lateral boundary conditions. The quasi-geostrophic model used by McGillicuddy and Robinson [1997] covered a 1,000 × 1,000-km area in the Sargasso Sea. Their estimate of a regional eddyinduced nitrate supply of $0.5 \mathrm{~mol} \mathrm{~m}^{-2}$ year-1 suggests that eddy pumping is sufficient to explain geochemical estimates of new production. However, although moving the lateral boundaries far away and thereby allowing for longer integration with a fully developed eddy field, this study used a simple nitrate consumption and restoring model in the vertical dimension. In particular, nitrate was restored right below the euphotic zone to climatological values at a timescale of 3 months to parameterize recharging of deep isopycnals by remineralization. This relaxation of vertical nutrient gradients to climatology implies that the mean gradients cannot freely adjust to the eddy field of the model.

\subsection{Basin-Scale Models}

The first basin-scale model used to investigate the impact of eddies was presented by Oschlies and Garçon [1998] who used a $1 / 3^{\circ}$ resolution $z$-level primitive-equation model into which satellite altimeter data were assimilated to ensure more realistic levels of eddy activity. With modeled eddy 
kinetic energy levels generally being lower than satellitederived observational estimates by some $30 \%$, and with a fully prognostic biogeochemistry everywhere within the model domain, this study suggested that eddies account for a nitrate supply of about $0.03 \mathrm{~mol} \mathrm{~m}^{-2}$ year-1 over the subtropical gyre, which is about the same size as the contribution by smallscale turbulent mixing across the pycnocline. Accordingly, and in contrast to most of the earlier regional models, the conclusion of that study was that the contribution by eddies is not sufficient to explain the apparent discrepancy between low direct measurements and high geochemical estimates of new production.

While the above study was only marginally eddy-resolving and, despite the assimilation of altimeter data did not fully reach observed levels of eddy activity, similar conclusions were reached by a subsequent study using a $1 / 9^{\circ}$ resolution eddy-resolving model [Oschlies, 2002a]. In fact, when comparing results of the eddy-permitting, eddy-resolving, and a highly viscous eddy-permitting (to mimic a coarseresolution model without changing the mean flow too much) model, the large-scale patterns look very similar. This is shown in Plate 1 for the simulated surface chlorophyll. All three model configurations use the same ecosystem model [Oschlies and Garçon, 1999], the same initial values, same boundary conditions, and same monthly mean atmospheric forcing fields. Apart from the closed boundaries, there are no restoring terms within the model domain, and for the upper ocean, the solution approaches a self-consistent statistically steady state within a few years. Naturally, the eddy-related conclusions derived from such a fully prognostic model are only as good as the model is able to reproduce at least the statistical moments of the observations. Close agreement with time-series data available at the BATS site was found for the simulated mean nitrate profiles as well as for the variance of vertical displacements of nitrate isosurfaces and their correlations with sea surface height. An investigation of the physical properties showed agreement also for spatial patterns of eddy kinetic energy, eddy length scales, spectral densities of sea-surface height variations, and for winter mixed-layer depths that became generally shallower when eddies were resolved [Oschlies, 2002b]. The latter feature was linked to the improved representation of instabilities within the mixed layer [Nurser and Zhang, 2000]. This process can actually lead to an eddy-induced reduction in annual nutrient supply in high latitudes where entrainment into the deepening winter mixed layer often dominates the annual budget.

Overall, all three model configurations showed relatively similar patterns of total nitrate input into the upper $126 \mathrm{~m}$ of the model, here taken as a proxy for the euphotic zone (Plate 2, Figure 2). Results do not change significantly when the $1 \%$ light level is taken as base of the euphotic zone as done by Oschlies [2002a]. Averaged over the entire model domain, nitrate supply varied by less than $2 \%$ among the three model configurations $\left(0.204 \mathrm{~mol} \mathrm{~m}^{-2}\right.$ year-1 $^{-1}$ in the viscous experiment, $0.202 \mathrm{~mol} \mathrm{~m}^{-2}$ year $^{-1}$ in the eddy-permitting experiment, and $0.205 \mathrm{~mol} \mathrm{~m}^{-2}$ year $^{-1}$ in the eddy-resolving experiment). This is comparable to the $2-3 \%$ increase obtained by switching from monthly mean forcing to daily atmospheric forcing.

One may look at the individual contributions to the total advective nitrate supply from the mean flow and the eddying flow in the following way:

$$
\int_{126 z \mathrm{~m}}^{0} \nabla \cdot \overline{(\mathbf{u N O})} d z=\left.\overline{w \mathrm{NO}_{3}}\right|_{126 \mathrm{~m}}+\int_{126 \mathrm{~m}}^{0} \nabla_{h} \cdot \overline{\mathbf{u}_{h} \mathrm{NO}_{3}} d z
$$

with

$$
\left.\overline{w \mathrm{NO}_{3}}\right|_{126 \mathrm{~m}}=\left.\bar{w} \overline{\mathrm{NO}_{3}}\right|_{126 \mathrm{~m}}+\left.\overline{w^{\prime} \mathrm{NO}_{3}^{\prime}}\right|_{126 \mathrm{~m}}
$$

and

$$
\nabla_{h} \cdot \overline{\mathbf{u}_{h} \mathrm{NO}_{3}}=\nabla_{h} \cdot \overline{\mathbf{u}}_{h} \overline{\mathrm{NO}_{3}}+\nabla_{h} \cdot \overline{\mathbf{u}_{h}^{\prime} \mathrm{NO}_{3}^{\prime}}
$$

where the overbar denotes the 3-year mean, and the prime denotes all deviations from the mean. Possible eddy effects on the mixing terms are not considered in this analysis. The first term on the right-hand side of (5) and (6), respectively, is referred to as the contribution of the mean flow and the second term as contribution of the fluctuating "eddy" flow. Note that the latter term does not only contain fluctuations associated with mesoscale eddies but also includes sub-mesoscale and seasonal variations.

The simulated nitrate supply is broken down into the individual contributions in Plate 3 that also includes the contribution by vertical mixing. The latter is dominant over large parts of the subpolar gyre where winter mixed-layer depths are deeper than the chosen 126-m reference depth for the euphotic zone. Nitrate supply by the mean advective transport (which, according to equations (1) to (3), has to vanish when integrated over volumes enclosed by nitrate isosurfaces) is positive only within relatively narrow bands near the equatorial upwelling and along the margins of the subtropical gyre where Ekman transport fluxes in significant amounts of nutrients across mean streamlines of the horizontal gyre circulation from nutrient-rich areas into the oligotrophic sugtropical gyre [Williams and Follows, 1998a]. The eddyinduced nitrate supply is positive almost everywhere within the subtropical gyre, reaching highest values of $0.1 \mathrm{~mol} \mathrm{~m}^{-2}$ 

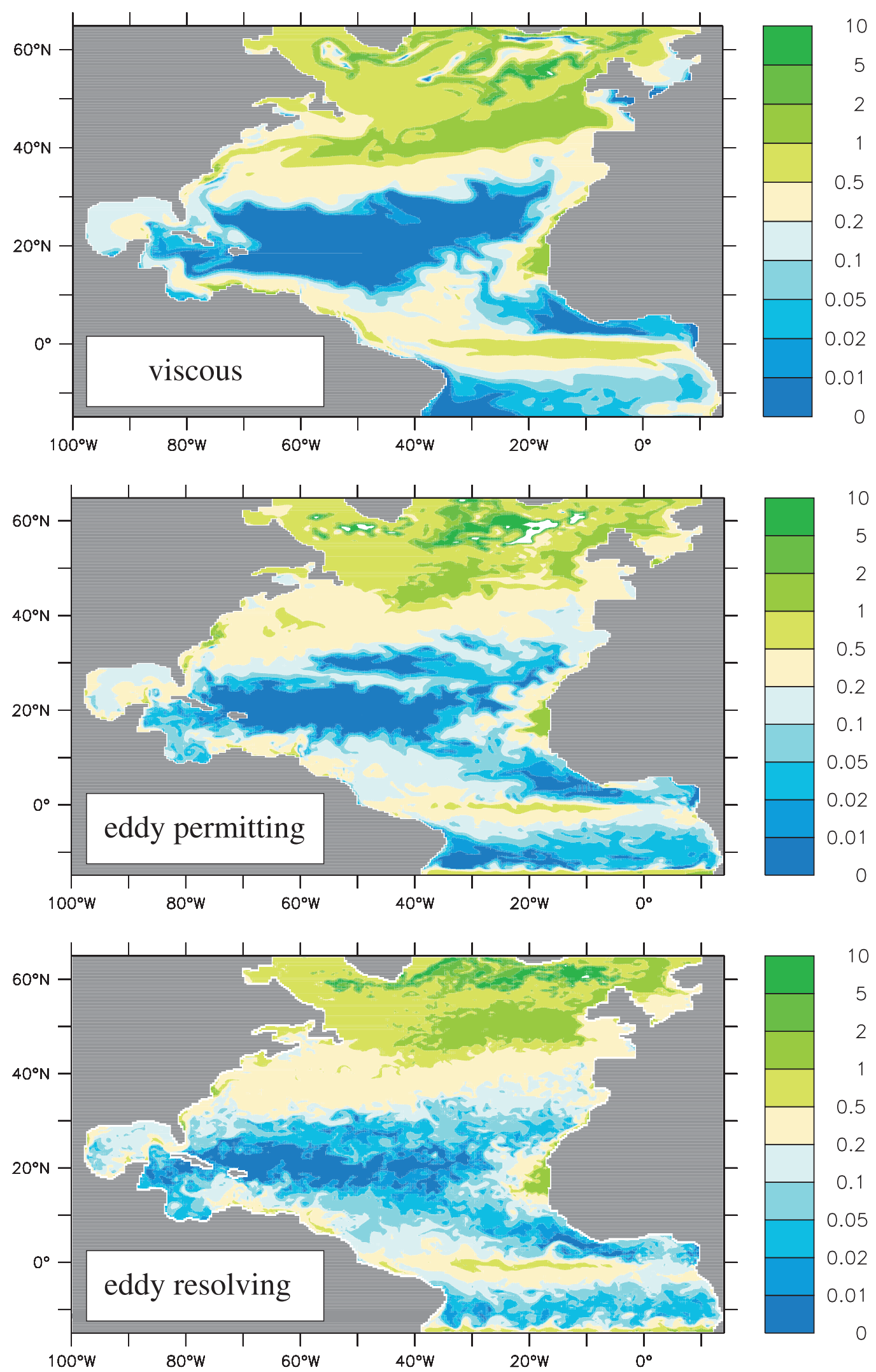
year ${ }^{-1}$ right at the margins of the gyre, whereas typical values are smaller than $0.05 \mathrm{~mol} \mathrm{~m}^{-2}$ year-1 $^{-1}$. It is interesting to note that the eddy-associated flux is negative over much of the subpolar North Atlantic, along the equator, and along a band extending from the upwelling region off West Africa. Decomposing the eddy contribution into vertical and horizontal components shows that the vertical eddy transport is largest in the Gulf Stream area where eddy formation and associated eddy pumping by lifting of isopycnals during eddy formation is most intense. Contributions of this mechanism reach values of $0.1 \mathrm{~mol} \mathrm{~m}^{-2}$ year $^{-1}$ only within the Gulf Stream, and in the subtropical gyre, values are usually smaller than 0.05 mol m-2 year $^{-1}$.

Somewhat larger nutrient fluxes are generated by the horizontal component of the eddying nitrate transport, with largest values of $0.2 \mathrm{~mol} \mathrm{~m}^{-2}$ year $^{-1}$ along the southern margin of the gyre in a narrow band along the North Equatorial Current. Here, the eddy-associated nitrate supply is just north of the input related to the Ekman-related mean flow, suggesting that eddies laterally mix the input by the mean flow further into the oligotrophic gyre. The zonal average of the eddyinduced nutrient fluxes into the upper $126 \mathrm{~m}$ of the model is displayed in Figure 3. The zonally averaged nitrate input by vertical eddy motions is positive only in the northern half of the subtropical gyre (north of $25^{\circ} \mathrm{N}$ ), while the zonally averaged input by lateral eddy motions has significant positive contributions also in the southern half. When averaged from $12^{\circ} \mathrm{N}$ to $40^{\circ} \mathrm{N}$, the total eddy-induced nitrate supply amounts to $0.01 \mathrm{~mol} \mathrm{~m}^{-2}$ year $^{-1}$ in this model. This figure results from an average negative contribution from vertical eddy motion $\left(-0.02 \mathrm{~mol} \mathrm{~m}^{-2}\right.$ year $\left.^{-1}\right)$ and a positive contribution from lateral eddy motions $\left(0.03 \mathrm{~mol} \mathrm{~m}^{-2}\right.$ year $\left.^{-1}\right)$.

A second basin-scale eddy-resolving modeling study was presented by McGillicuddy et al. [2003]. While they used a slightly higher spatial resolution of $0.1^{\circ}$ than the $1 / 9^{\circ}$ model of Oschlies [2002a], the general architecture of the $z$-level primitive-equation physical model was the same. The main difference between these two studies lies in the use of artificial restoring: Oschlies [2002a] used a nutrient/phytoplankton/ zooplankton/detritus-type ecosystem model coupled to the circulation field in fully prognostic mode at all depths without any restoring to climatological nutrient fields, McGillicuddy et al. [2003] used a nutrient transport model with nitrate being consumed at rates depending on temperature and light at depths shallower than $z=104 \mathrm{~m}$ and being restored at depths below $z=104 \mathrm{~m}$ to density-dependent nitrate fields derived from projecting World Ocean Atlas [Conkright et al., 1998] nitrate data onto the mean density field of the model. The crucial parameter of this model is the restoring timescale of the "deep" nitrate field. McGillicuddy et al. [2003] performed sensitivity experiments using restoring times of 10, 30, and 60 days. However, results were shown only for the 10-day restoring timescale. As pointed out by Martin and Pondaven [2003], 10 days is unrealistically short compared to observations at Bermuda [McNeil et $a l ., 1999]$ and may substantially overestimate eddy-induced nutrient supply by as much as an order of magnitude.

While many features in the two modeling studies turned out to be very similar in both qualitative and quantitative ways, substantial differences were found in the pattern and size of the nutrient input by the eddy-associated vertical advection. The model of McGillicuddy et al. [2003] predicted positive values essentially everywhere over the subtropical and tropical Atlantic, in some regions exceeding $0.3 \mathrm{~mol} \mathrm{~N}$ $\mathrm{m}^{-2}$ year $^{-1}$. The model of Oschlies [2002a], on the other hand, restricts positive values of magnitudes typically smaller than $0.05 \mathrm{~mol} \mathrm{~m}^{-2}$ year ${ }^{-1}$ mostly to the northwestern part of the gyre where eddy activity is largest. It is interesting to note that both models show roughly similar results for the effect of eddies on the lateral nutrient supply while they differ by a factor of 5-10 in the eddy-associated vertical nutrient supply. It is most likely that this difference is caused by the different treatment of nutrient recharging below the euphotic zone.

\section{CONCLUDING DISCUSSION}

The ocean is full of eddies, and individual eddy events have naturally been observed in biogeochemical observational campaigns. It is difficult to argue that eddies should be under-represented rather than over-represented in the growing observational data base, particularly as this underrepresentation would seem to be similar for all ocean basins. Given the growing interest in eddies and several dedicated studies with cruise tracks carefully arranged to track eddies detected by remote sensing, one might even ask whether our data bases may over-represent the more "interesting" eddy features. In any case, with an ever-increasing number of observations, the average of the available observations converges to the true average, and there remains less and less chance for a systematic statistical bias needed to explain the apparent observational discrepancies by means of unobserved episodic events. However, given the available observations of eddy-induced nutrient supply [Falkowski et al., 1991; McNeil et al., 1999] and a large number of modeling studies, there is unequivocal agreement that eddies

Plate 1. (Opposite) Simulated surface chlorophyll for 1 May using a chlorophyll-to-nitrogen ratio of $1.59 \mathrm{mg}$ Chl (mmol N) $)^{-1}$. Top: $1 / 3$ degree model with large lateral viscosity $\left(10^{3} \mathrm{~m}^{2} \mathrm{~s}^{-1}\right)$. Middle: $1 / 3$ degree model. Bottom: 1/9 degree model. 

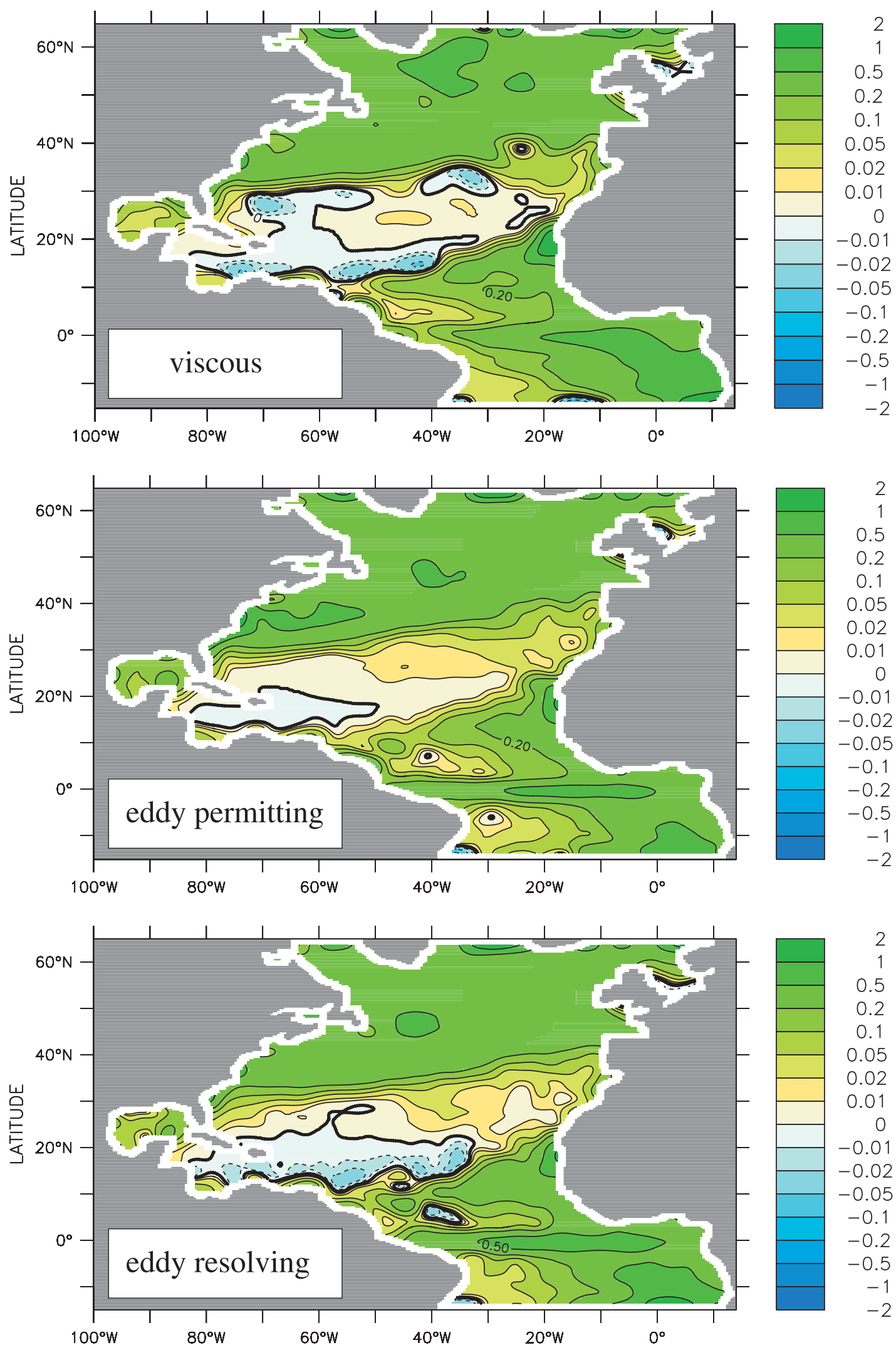

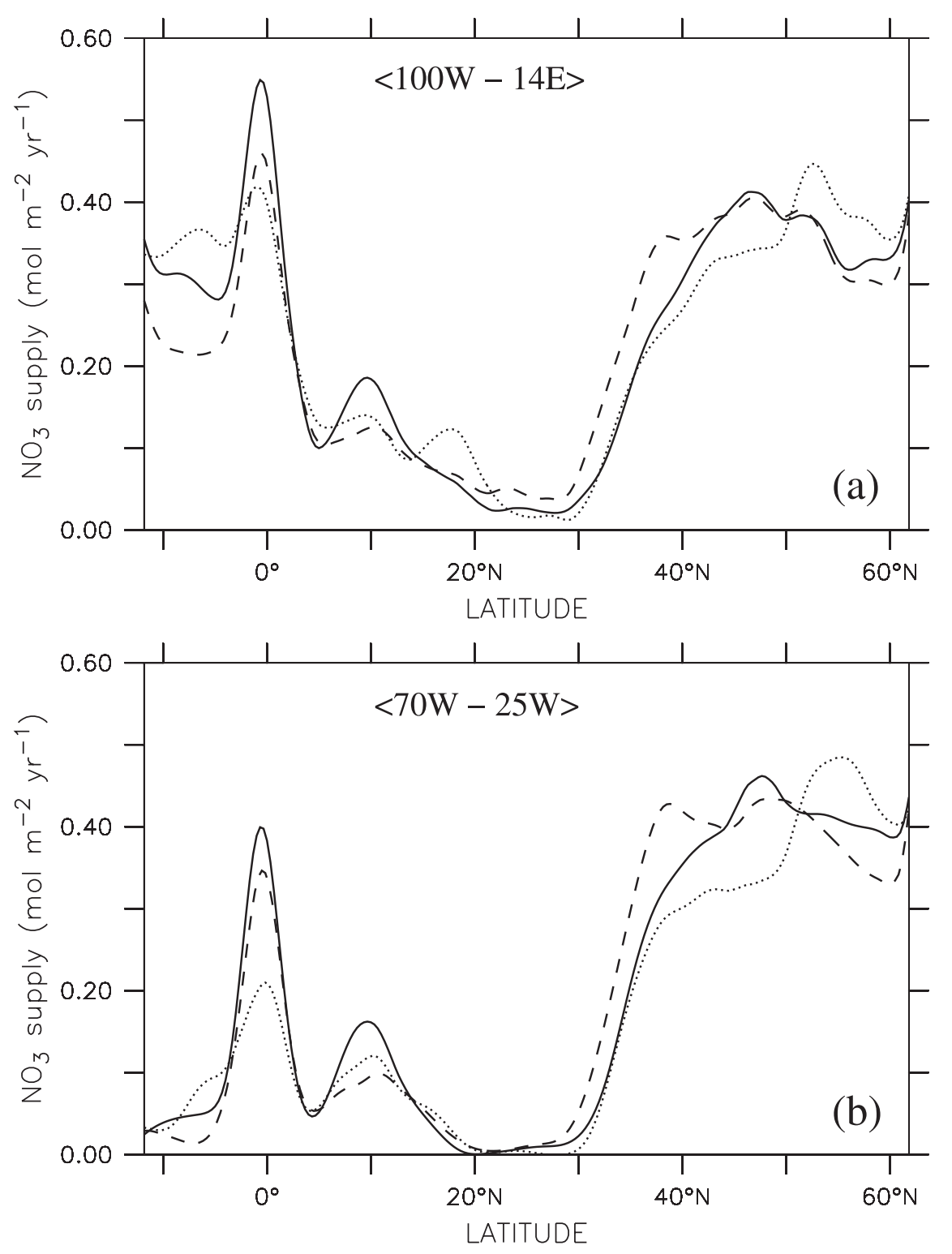

Figure 2. Zonally averaged simulated annual-mean nitrate supply to the upper $126 \mathrm{~m}$ of the three models. (a) Basin-wide zonal averages. (b) Zonal averages between $70^{\circ} \mathrm{W}$ and $25^{\circ} \mathrm{W}$ to exclude subtropical coastal upwelling regions. Results are shown for the eddy-resolving $1 / 9^{\circ}$ model (solid lines), the eddy-permitting $1 / 3^{\circ}$ model (dashed lines), and the viscous $1 / 3^{\circ}$ model (dotted lines). Units are mol $\mathrm{N} \mathrm{m}^{-2}$ year $^{-1}$.

do play some role in the nutrient supply to the oligotrophic gyres. Extrapolations of individual events to larger areas and longer time spans remain difficult and vary from a mere $20 \%$ enhancement of biological production by mesoscale eddies [Falkowski et al., 1991] to a 100-200\% enhancement [McGillicuddy et al., 1998].
Modeling studies that can be expected to be particularly useful for inter- and extrapolation of individual observations have also proposed a large variety of values for the average extra nutrient supply generated by eddies, and results seem to fall into two categories: high estimates obtained by models that recharge sub-euphotic zone nutrients by restoring to climatology

Plate 2. (Opposite) Simulated annual-mean nitrate supply to the upper $126 \mathrm{~m}$ of the model. Top: 1/3 degree model with large lateral viscosity $\left(10^{3} \mathrm{~m}^{2} \mathrm{~s}^{-1}\right)$. Middle: $1 / 3$ degree model. Bottom: $1 / 9$ degree model. Units are mol $\mathrm{N} \mathrm{m}^{-2}$ year $^{-1}$. 

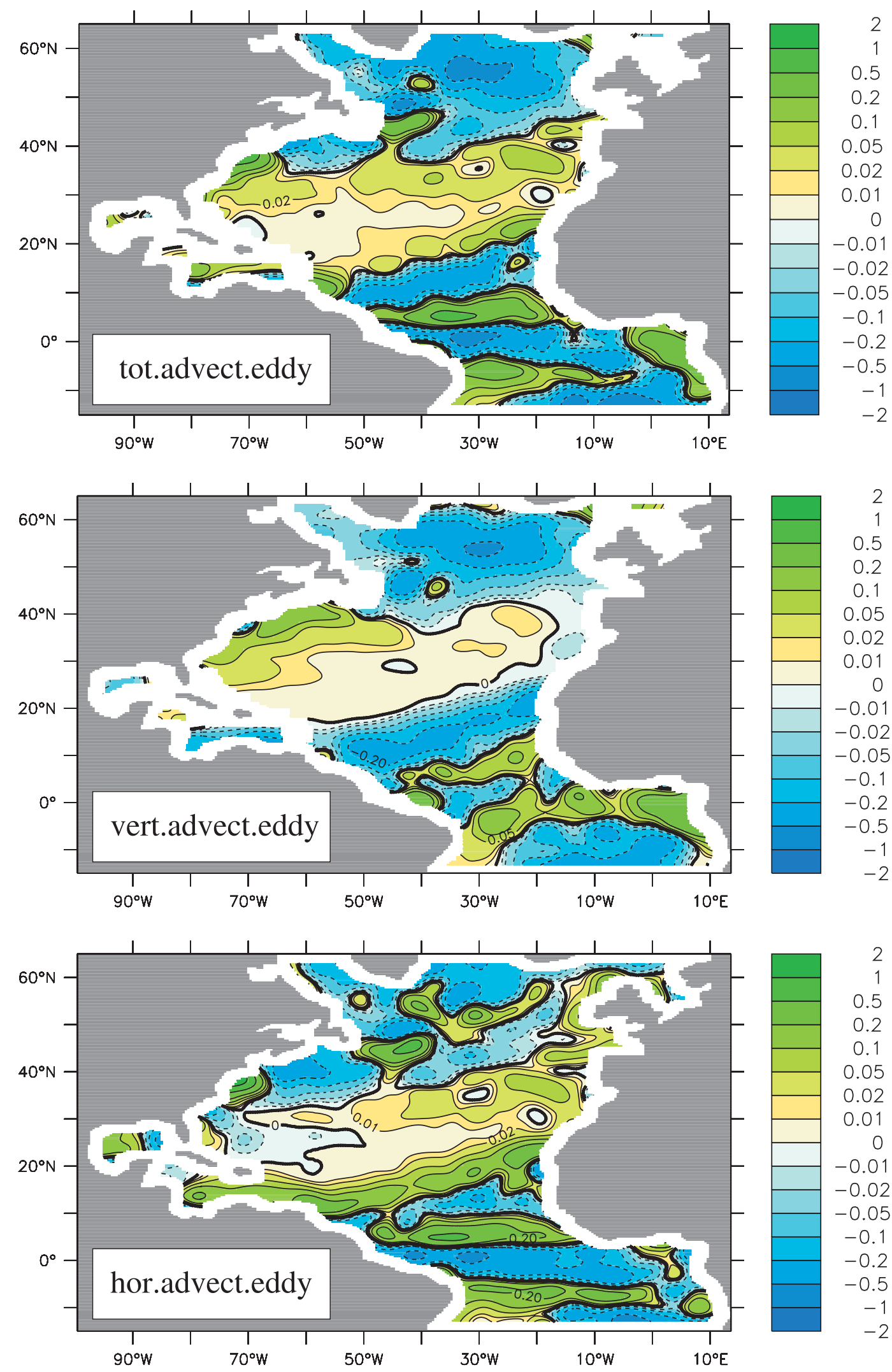


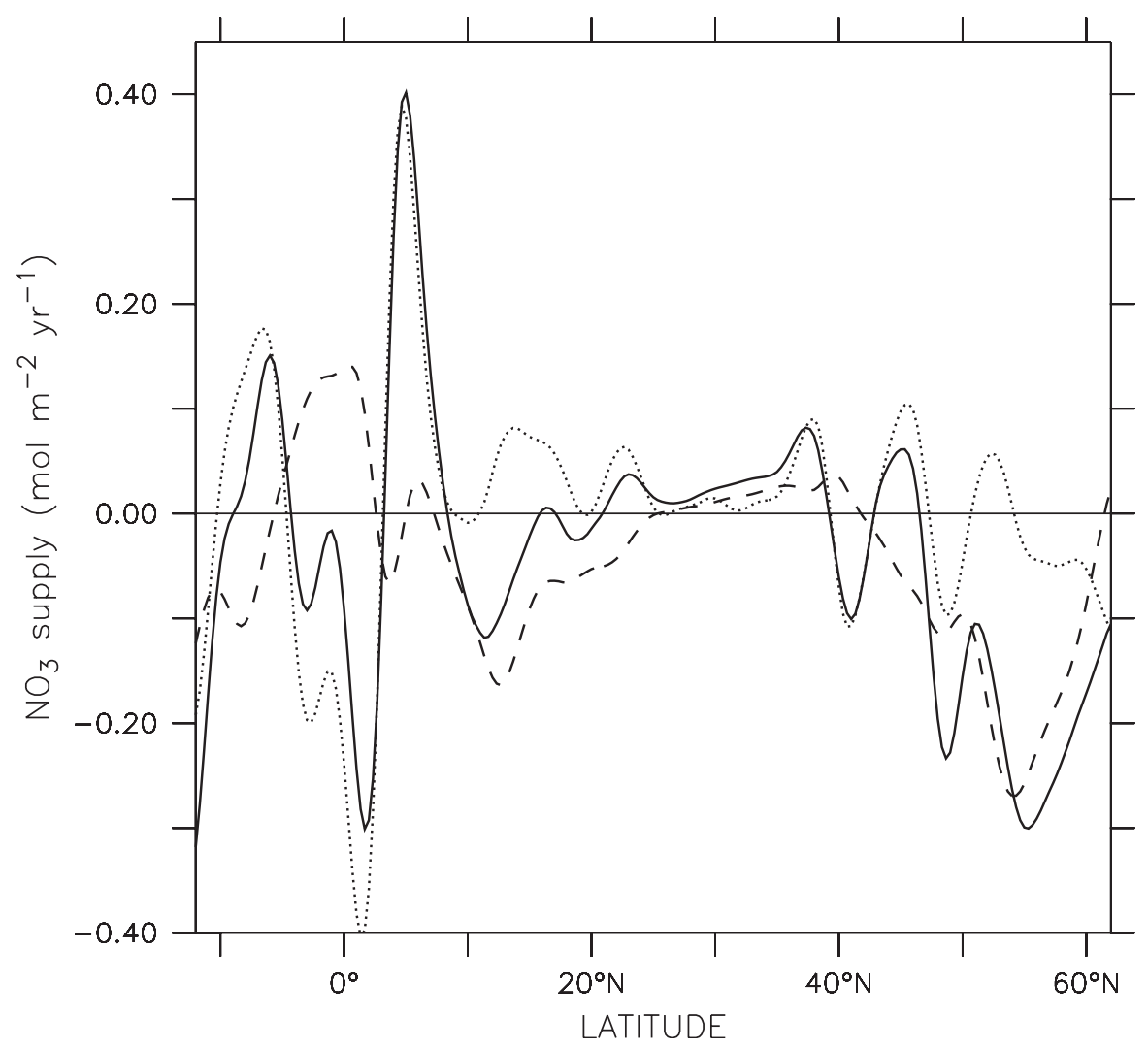

Figure 3. Zonally averaged simulated eddy-induced nitrate supply to the upper $126 \mathrm{~m}$ of the eddy-resolving $1 / 9^{\circ}$ model. The solid line refers to the total advective supply by eddies, the dashed line to the vertical eddy-induced supply, and the dotted line to the lateral eddy-induced supply. Units are $\mathrm{mol} \mathrm{N} \mathrm{m}^{-2} \mathrm{yr}^{-1}$.

[McGillicuddy and Robinson, 1997; McGillicuddy et al., 1998, 2003; Siegel et al., 1999] and models that explicitly compute remineralization and mixing of nutrients [Oschlies and Garçon, 1998; Spall and Richards, 2000; Oschlies, 2002a; Martin and Pondaven, 2003]. The later two studies have shown that the "recharging by restoring" method leads, for the restoring timescales employed, to a significant overestimate of the estimated nutrient supply by almost an order of magnitude. Remarkably, the different modeling studies seem to agree upon the role of lateral stirring of nutrients by eddies across the margins of the oligotrophic subtropical gyres [Lee and Williams, 2000; Oschlies, 2002a; McGillicuddy et al., 2003].

While it remains to be seen whether longer restoring times of the restoring-type models bring results of the two model categories into closer agreement, we do not yet know whether any of the fully prognostic models predict the eddy- induced nutrient flux correctly. Realising that sinking is a diapycnal transport, recharging will have to involve diapycnal transports as well. Such fluxes will not only affect nutrients but also any other tracer such as temperature. To the extent that models tend to underestimate subtropical surface temperatures, diapycnal fluxes are likely too large rather than too small in these models, suggesting that the modelderived eddy-induced nutrient fluxes may be overestimates rather than underestimates. Clearly, more dedicated observational programs will help to put better constraints on our model results. This will have to cover both individual eddies including sub-mesoscale diapycnal transports at the eddies' margins as well as time-series and synoptic remote sensing studies to improve our knowledge about the statistics of episodic nutrient supplies. It may well be that this will eventually confirm the early conservative estimate of Falkowski et

Plate 3. (Opposite) Simulated annual-mean nitrate supply to the upper $126 \mathrm{~m}$ of the $1 / 9$ degree eddy-resolving model. Top: Nitrate supply induced by the eddy transport, $\int_{126 \mathrm{~m}}^{0} \nabla \cdot \overline{\left(u^{\prime} \mathrm{NO}_{3}^{\prime}\right)} d z$. Middle: Nitrate supply associated with the vertical eddy component, $\left.\overline{w^{\prime} \mathrm{NO}_{3}^{\prime}}\right|_{126 \mathrm{~m}}$. Bottom: Nitrate supply associated with the lateral eddy component, $\int_{126 \mathrm{~m}}^{0} \nabla_{h} \cdot\left(\overline{u_{h}{ }^{\prime} \mathrm{NO}_{3}^{\prime}}\right) d z$. Units are mol $\mathrm{N} \mathrm{m}^{-2}$ year $^{-1}$. 
al. [1991] that puts the eddy-induced average enhancement of biological production into the range of $20 \%$.

A possible impact of eddies on biogeochemical cycles not discussed in this study is their role in structuring pelagic ecosystems. By enclosing water masses for weeks to months, eddies can isolate communities and move them around. The disturbances associated with the eddies may select for certain size classes [Rodriguez et al., 2001] and/or phytoplankton functional types [Vaillancourt et al., 2003; Benitez-Nelson, et al., 2007]. This may well affect fluxes of biogeochemical tracers, but the magnitude and even the direction of any net impact is not yet known.

As it stands, the subtropical desert conundrum, which originally pointed to the possible role of eddies in biogeochemical cycles [Jenkins, 1982], has not yet been resolved. Eddies can explain some portion of the apparent observational discrepancy between low nitrate supply and large oxygen consumption at depth (perhaps some $10-20 \%$, about $0.05 \mathrm{~mol} \mathrm{~N} \mathrm{~m}^{-2}$ year ${ }^{-1}$ with lateral eddy stirring being at least as important as vertical eddy pumping). There is mounting evidence that in addition to the contribution by eddies, other previously unaccounted transport mechanisms like mixing by double diffusion $\left[\mathrm{OS}_{\mathrm{S}}\right.$ chlies et al., 2003] and sub-mesoscale upwelling events [Lévy et al., 2001] may play a significant role. However, given that diapycnal mixing will also mix temperature, the constraints imposed by observed surface heat fluxes make it difficult to imagine that we have missed order-of-magnitude increases in near-surface diapycnal mixing that would be required to resolve the conundrum by mixing arguments. Possible alternative explanations include incorrect assumptions about elemental stoichiometry when comparing nitrogen fluxes and oxygen consumption. For example, subduction of dissolved organic carbon can lead to oxygen consumption without requiring any nitrogen supply into the overlying surface waters. Additional nitrogen sources like nitrogen fixation [Hansell et al., 2004] or atmospheric dust supply [Baker et al., 2003] will also help to close the apparent observational discrepancy between low supply of dissolved inorganic nitrogen to the subtropical surface layer and high rates of oxygen consumption at depth.

Acknowledgments. I thank the reviewers for their helpful and constructive comments that helped to improve the text and Matthew Hecht and Hiroyasu Hasumi for giving me the opportunity to participate in this book and for their help and effort in the production process.

\section{REFERENCES}

Abraham, E. R. (1998), The generation of plankton patchiness by turbulent stirring, Nature, 391, 577-580.

Bainbridge, R. (1957), The size, shape and density of marine phytoplankton concentrations, Biol. Rev., 32, 91-115.
Baker, A. R., S. D. Kelly, K. F. Biswas, M. Witt, and T. D. Jickells (2003), Atmospheric deposition of nutrients to the Atlantic Ocean, Geophys. Res. Lett., 30(24), 2296, doi:10.1029/GL018518.

Benitez-Nelson, C. R., et al. (2007), Mesoscale eddies drive increased silica export in the subtropical Pacific Ocean, Science, 316, 1017-1021.

Conkright, M. E., et al. (1998), World Ocean database 1998, CDROM Data Set Documentation. O.C.L., National Oceanographic Data Center Internal Report 14, 111 pp.

Conkright, M. E., H. E. Garcia, T. D. O'Brien, R. A. Locarnini, T. P. Boyer, C. Stephens, and J. I. Antonov (2002), World Ocean Atlas 2001, Volume 4: Nutrients, in NOAA Atlas NESDIS 54, edited by S. Levitus, 392 pp , US Government Printing Office, Washington, DC.

Dadou, I., V. Garçon, V. Andersen, G. R. Flierl, and C. S. Davis (1996), Impact of the North Equatorial Current meandering on a pelagic ecosystem: A modeling approach, J. Mar. Res., 54, 311-342.

Dandonneau, Y., A. Vega, H. Loisel, Y. du Penhoat, C. Menkes (2003), Oceanic Rossby waves acting as a "Hay Rake" for ecosystem floating by-products, Science, 302, 1548-1551.

del Giorgio, P. A., J. J. Cole, and A. Cimbleris (1997), Respiration rates in bacteria production exceed phytoplankton production in unproductive aquatic systems, Nature, 385, 148-151.

Doney, S. C., D. M. Glover, S. J. McCue, and M. Fuentes (2003), Mesoscale variability of Sea-viewing Wide Field-of-view Sensor (SeaWiFS) satellite ocean color: Global patterns and spatial scales, J. Geophys. Res., 108(C2), 3024, doi:10.1029/ 2001JC000843.

Dugdale, R. C., and J. J. Goering (1967), Uptake of new and regenerated forms of nitrogen in marine production, Limnol. Ocean$o g r ., 12,196-206$.

Eppley, R. W., and B. J. Peterson (1979), Particulate organic matter flux and planktonic new production in the deep ocean, Nature, $282,677-680$.

Falkowski, P. G., D. Ziemann, Z. Kolber, and P. K. Bienfang (1991), Role of eddy pumping in enhancing primary production in the ocean, Nature, 352, 55-58.

Fasham, M. J. R., T. Platt, B. Irwin, and K. Jones (1985), Factors affecting the spatial pattern of the deep chlorophyll maximum in the region of the Azores front, Prog. Oceanogr., 14, 129-165.

Flierl, G. R., and C. S. Davis (1993), Biological effects of Gulf Stream meandering, J. Mar. Res., 51, 529-560.

Franks, P. J. S., J. S. Wroblewski, and G. R. Flierl (1986), Prediction of phytoplankton growth in response to the frictional decay of a warm core ring, J. Geophys. Res., 91, 7603-7610.

Garçon, V., A. Oschlies, S. Doney, D. McGillicuddy, and J. Waniek (2001), The role of mesoscale variability on plankton dynamics in the North Atlantic, Deep-Sea Res. II, 48, 2199-2226.

Greatbatch, R. J., X. Zhai, C. Eden, and D. Olbers (2007), The possible role in the ocean heat budget of eddy-induced mixing due to air-sea interaction, Geophys. Res. Lett., 34, L07604, doi:10.1029/2007GL029533.

Hansell, D. A., N. R. Bates, and D. B. Olson (2004), Excess nitrate and nitrogen fixation in the North Atlantic Ocean, Mar. Chem., $84,243-265$. 
Jenkins, W. J. (1982), Oxygen utilization rates in North Atlantic subtropical gyre and primary production in oligotrophic systems, Nature, 300, 246-248.

Jenkins, W. J. (1988), Nitrate flux into the euphotic zone near Bermuda, Nature, 331, 521-523.

Jenkins, W. J., and J. Goldman (1985), Seasonal oxygen cycling and primary production in the Sargasso Sea, J. Mar. Res., 43, 465-491.

Karl, D. M., E. A. Laws, P. Morris, P. J. leB. Williams, and S. Emerson (2003), Metabolic balance of the open sea, Nature, 426, 32.

Kawamiya, M., and A. Oschlies (2001), Formation of a basin-scale surface chlorophyll pattern by Rossby waves, Geophys. Res. Lett., 28, 4139-4142.

Lee, M.-M., and R. G. Williams (2000), Examining how eddies affect biological production through the lateral transport and diffusion of nutrients, J. Mar. Res., 58, 895-917.

Lévy, M. (2003), Mesoscale variability of phytoplankton and of new production: Impact of the large-scale nutrient distribution, J. Geophys. Res., 108(C11), 3358, doi:10.1029/2002JC001577.

Lévy, M., P. Klein, and A.-M. Treguier (2001), Impacts of submesoscale physics on phytoplankton production and subduction, J. Mar. Res., 59, 535-565.

Lewis, M. R., W. G. Harrison, N. S. Oakey, D. Herbert, and T. Platt (1986), Vertical nitrate fluxes in the oligotrophic ocea, Science, 234, 870-873.

Lohrenz, S. E., G. A. Knauer, V. L. Asper, M. Tuel, A. F. Michaels, and A. H. Knap (1992), Seasonal variability in primary production and particle flux in the northwestern Sargasso Sea: US JGOFS Bermuda Atlantic Time-Series Study, Deep-Sea Res., 39, 1373-1391.

Mahadevan, A., and D. Archer (2000), Modeling the impact of fronts and mesoscale circulation on the nutrient supply and biogeochemistry of the upper ocean, J. Geophys. Res., 105, 1209-1225.

Mahadevan, A., and J. W. Campbell (2002), Biogeochemical patchiness at the sea surface, Geophys. Res. Lett., 29(19), 1926, doi:10.1029/2001GL014116.

Mahadevan, A., M. Lévy, and L. Mémery (2004), Mesoscale variability of sea surface $\mathrm{pCO}_{2}$ : What does it respond to?, Global Biogeochem. Cycles, 18, GB1017, doi:10.1029/2003GB002102.

Maier-Reimer, E., U. Mikolajewicz, and A. Winguth (1996), Future ocean uptake of $\mathrm{CO}_{2}$ : Interaction between ocean circulation and biology, Clim. Dyn., 12, 711-721.

Martin, A. P. (2003), Phytoplankton patchiness: the role of lateral stirring and mixing, Prog. Oceanogr., 57, 125-174.

Martin, A. P., and P. Pondaven (2003), On estimates for the vertical nitrate flux due to eddy pumping, J. Geophys. Res., 108(9), 3359, doi:10.1029/2003JC001841.

Martin, A. P., and K. J. Richards (2001), Mechanisms for vertical nutrient transport within a North Atlantic mesoscale eddy, DeepSea Res. II, 48, 757-773.

McGillicuddy, D. J., Jr., and A. R. Robinson (1997), Eddy-induced nutrient supply and new production in the Sargasso Sea, DeepSea Res. I, 44, 1427-1450.

McGillicuddy, D. J., Jr., A. R. Robinson, and J. J. McCarthy (1995), Coupled physical and biological modeling of the spring bloom in the North Atlantic (II): Three dimensional bloom and post-bloom processes, Deep-Sea Res. I, 42, 1359-1398.
McGillicuddy, D. J., Jr., A. R. Robinson, D. A. Siegel, H. W. Jannasch, R. Johnson, T. D. Dickey, J. McNeil, A. F. Michaels, and A. H. Knap (1998), Influence of mesoscale eddies on new production in the Sargasso Sea, Nature, 394, 263-266.

McGillicuddy, D. J., Jr., R. Johnson, D. A. Siegel, A. F. Michaels, N. R. Bates, and A. H. Knap (1999), Mesoscale variations of biogeochemical properties in the Sargasso Sea, J. Geophys. Res., 104, 13,381-13,394.

McGillicuddy, D. J., Jr., L. A. Anderson, S. C. Doney, and M. E. Maltrud (2003), Eddy-driven sources and sinks of nutrients in the upper ocean: Results from a $0.1^{\circ}$ resolution model of the North Atlantic, Global Biogeochem. Cycles, 17(2), 1035, doi:10.1029/ 2002 GB001987.

McGillicuddy, D. J., L. A. Anderson, N. R. Bates, T. Bibby, K. O. Buesseler, C. A. Carlson, C. S. Davis, C. Ewart, P. G. Folkowski, S. A. Goldthwait, D. A. Hansell, W. J. Jenkins, R. Johnson, V. K. Kosnyrev, J. R. Ledwell, Q. P. Li, D. A Siegel, and D. K. Steinberg. (2007), Eddy/wind interactions stimulate extraordinary mid ocean plankton blooms, Science, 316, 1021-1026.

McNeil, J. D., H. W. Jannasch, T. Dickey, D. McGillicuddy, M. Brzezinski, and C. M. Sakamoto (1999), New chemical, biooptical and physical observations of upper ocean response to the passage of a mesoscale eddy off Bermuda, J. Geophys. Res., 104, $15,537-15,548$.

Morel, A., B. Gentili, H. Claustre, M. Babin, A. Bricaud, J. Ras, and F. Tieche (2007), Optical properties of the "clearest" natural waters, Limnol. Oceanogr., 52, 217-229.

Nurser, A. J. G., and J. W. Zhang (2000), Eddy-induced mixed layer shallowing and mixed layer/thermocline exchange, $\mathrm{J}$. Geophys. Res., 105, 21,851-21,868.

Onken, R. (1992), Mesoscale upwelling and density finestructure in the seasonal thermocline-Adynamical model, J. Phys. Oceanogr., 22, 1257-1273.

Oschlies, A. (2002a), Can eddies make ocean deserts bloom? Global Biogeochem. Cycles, 16(4), 1106, doi:10.1029/2001GB001830.

Oschlies, A. (2002b), Improved representation of upper ocean dynamics and mixed layer depths in a model of the North Atlantic on switching from eddy-permitting to eddy-resolving grid resolution, J. Phys. Oceanogr., 32, 2277-2298.

Oschlies, A. (2002c), Nutrient supply to the surface waters of the North Atlantic: A model study, J. Geophys. Res., 107(C5), 3046 doi:10.1029/2000JC000275.

Oschlies, A., and V. Garçon (1998), Eddy-induced enhancement of primary production in a model of the North Atlantic Ocean, Nature, 394, 266-269.

Oschlies, A., and V. Garçon (1999), An eddy-permitting coupled physical-biological model of the North Atlantic 1 . Sensitivity to advection numerics and mixed layer physics, Global Biogeochem. Cycles, 13, 135-160.

Oschlies, A., and P. Kähler (2004), Biotic contribution to air-sea fluxes of $\mathrm{CO}_{2}$ and $\mathrm{O}_{2}$ and its relation to new production, export production, and net community production, Global Biogeochem. Cycles, 18, GB1015, doi:10.1029/2003GB002094.

Oschlies, A., H. Dietze, and P. Kähler (2003), Salt-finger driven enhancement of upper-ocean nutrient supply, Geophys. Res. Lett., 30(23), 2204, doi:10.1029/2003GL018552. 
Plattner, G.-K., N. Gruber, H. Frenzel, and J. C. McWilliams (2005), Decoupling marine export production from new production, Geophys. Res. Lett., 32, L11612, doi:10.1029/2005GL022660.

Radko, T., and J. Marshall (2004), Eddy-induced diapycnal fluxes and their role in the maintenance of the thermocline, $J$. Phys. Oceanogr., 34, 372-383,

Rodriguez, J., J. Tintore, J. T. Allen, J. M. Blanco, D. Gomis, A. Reul, J. Ruiz, V. Rodriguez, F. Echevarria, and F. Jimenez-Gomez (2001), Mesoscale vertical motion and the size structure of phytoplankton in the ocean, Nature, 410, 360-363.

Sarmiento, J. L., G. Thiele, R. M. Key, and W. S. Moore (1990), Oxygen and nitrate new production and remineralization in the North Atlantic subtropical gyre, J. Geophys. Res., 95, $18,303-18,315$.

Siegel, D. A., D. J. McGillicuddy, Jr., and E. A. Fields (1999), Mesoscale eddies, satellite altimetry, and new production in the Sargasso Sea, J. Geophys. Res., 104, 13,359-13,379.

Spall, S. A., and K. J. Richards (2000), A numerical model of mesoscale frontal instabilities and plankton dynamics. 1. Model formulation and initial experiments, Deep-Sea Res. I, 47, 1261-1301.

Spitzer, W. S., and W. J. Jenkins (1989), Rates of vertical mixing, gas exchange and mew production: estimates from seasonal gas cycles in the upper ocean near Bermuda, J. Mar. Res., 47, 169-196.

Strass, V. H. (1992), Chlorophyll patchiness caused by mesoscale upwelling at fronts, Deep-Sea Res., 39, 75-96.

Strutton, P. G., J. P. Ryan, and F. P. Chavez (2001), Enhanced chlorophyll associated with tropical instability waves in the equatorial Pacific, Geophys. Res. Lett., 28, 2005-2008.

Uz, B. M., J. A. Yoder, and V. Osychny (2001), Pumping of nutrients to ocean surface waters by the advection of propagating planetary waves, Nature, 409, 597-600.

Vaillancourt, R. D., J. Marra, M. P. Seki, M. L. Parsons, and R. R. Bidigare (2003), Impact of a cyclonic eddy on phytoplankton community structure and photosynthetic competency in the subtropical North Pacific Ocean, Deep-Sea Res. I, 50, 829-847.
Volk, T., and M. I. Hoffert (1985), Ocean carbon pumps: Analysis of relative strengths and efficiencies in ocean-driven atmospheric $\mathrm{CO}_{2}$ changes, in The Carbon Cycle and Atmospheric $\mathrm{CO}_{2}$ : Natural Variations Archean to Present, Geophys. Monogr. Ser., vol. 32, edited by E.T. Sundquist and W.S. Broecker, pp. 99-110, AGU, Washington, D.C.

Washburn, L., B. M. Emery, B. H. Jones, and D. G. Ondercin (1998), Eddy stirring and phytoplankton patchiness in the subarctic North Atlantic in late summer, Deep-Sea Res. I, 45, 1411-1439.

Williams, P. L. le B., P. J. Morris, and D. M. Karl (2004), Net community production and metabolic balance at the oligotrophic ocean site, station ALOHA, Deep-Sea Res. I, 51, 1563-1578.

Williams, R. G., and M. J. Follows (1998a), The Ekman transfer of nutrients and maintenance of new production over the North Atlantic, Deep-Sea Res. I, 45, 461-489.

Williams, R. G., and M. J. Follows (1998b), Eddies make ocean deserts bloom., Nature, 394, 228-229.

Williams, R. G., and M. J. Follows (2003), Physical transport of nutrients and the maintenance of biological production, in Ocean Biogeochemistry, pp. 19-51, edited by M. J. R. Fasham, Global Change IGBP Series, Springer,

Woods, J. D. (1988), Mesoscale upwelling and primary production, in Toward a Theory on Biological-Physical Interactions in The World Ocean, edited by B. J. Rothschild, D. Reidel, $650 \mathrm{pp}$.

Yoder, J. A., S. G. Ackleson, R. T. Barber, P. Flament, and W. M. Balch (1994), A line in the sea, Nature, 371, 689-692.

Yoshimori, A., and M. J. Kishi (1994), Effects of interaction between two warm-core rings on phytoplankton distribution, DeepSea Res. I, 41, 1039-1052.

A. Oschlies, IFM-GEOMAR, Leibniz-Institut für Meereswissenschaften an der Universität Kiel, Düsternbrooker Weg 20, D-24105 Kiel, Germany. (aoschlies@ifmgeomar.de) 